\title{
UNSTEADY BOUNDARY LAYER FLOW ALONG A STRETCHING CYLINDER AN ANALYTICAL SOLUTION
}

\author{
M.Y. Akl \\ Department of Engineering Mathematics and Physics, \\ Faculty of Engineering, Benha University, Cairo, Egypt
}

Received 2013-11-12; Revised 2014-02-06; Accepted 2014-02-17

\begin{abstract}
The axisymetric laminar boundary layer unsteady flow along a continuously stretching cylinder immersed in a viscous and incompressible fluid is studied. The governing partial boundary layer equations in cylindrical form are first transformed into ordinary differential equations these equations are solved analytically using the optimal modified Homotopy Asymptotic method in order to get a closed form solution for the dimensionless functions $f$ and è. The main object of this study is to investigate the effect of an unsteady motion of a stretching cylinder on the flow and heat transfer characteristics such as surface skin friction and surface heat flux. These characteristics have a direct effect on the quality of the final product of the fiber manufacturing and extrusion processes. Considerable effects were found for the dynamic parameter $(\gamma)$, the curvature parameter $(\rho)$ and the prandtl number (pr) on the velocity and the heat transfer.
\end{abstract}

Keywords: Optimal Homotopy Asymptotic Method, Stretching Cylinder, Boundary Layer Flow, Unsteady Flow

\section{INTRODUCTION}

The boundary layer flow and heat transfer of stretching flat plates or cylinders are very important in fiber technology and extrusion processes. The production of sheeting material arises in a number of industrial manufacturing processes and includes both metal and polymer sheets. We have many applications such as the cooling of an infinite metallic plate in a cooling bath, the boundary layer along material handling conveyers, the aerodynamic extrusion of plastic sheets, the boundary layer along a liquid film in condensation processes, paper production, glass blowing, metal spinning, drawing plastic films and polymer extrusion. The quality of the final product depends on the rate of heat transfer at the stretching surface. Sakiadis (1961) was the first to consider the boundary layer flow on a moving continuous solid surface. Crane (1970) extended this concept to a stretching sheet with linearly varying surface speed and presented an exact analytical solution for the steady two-dimensional stretching of a surface in a quiescent fluid. Then many authors considered various aspects of this problem and obtained similarity solutions. A similarity solution is one in which the number of independent variables is reduced by at least one, usually by a coordinate transformation. The idea is analogous to dimensional analysis, but instead of parameters the coordinates themselves are collapsed into dimensionless groups that scale the velocities (White, 2006). The boundary layer flow due to a stretching surface in a quiescent viscous and incompressible fluid when the buoyancy forces are taken into consideration have been considered by Daskalakis (1993), Chen (1998; 2000), Lin and Chen (1998), Ali (2004), Partha et al. (2005) and Ishak et al. (2007) (Grubka and Bobba, 1985; Daskalakis, 1993). Lin and Shih (1980; 1981), considered the boundary layer and heat transfer along horizontally and vertically moving cylinders with constant velocity and found that the similarity solutions could not be obtained due to the curvature effect of the cylinder. The case of stretching sheet is studied by Grubka and Bobba (1985) and Ali (1994), this study is extended by Ishak and Nazar (2009), to the case of stretching cylinder. In this study we consider a 
stretching cylinder in an unsteady flow and have been solved analytically.

\section{FORMULATION OF THE PROBLEM}

Consider an unsteady, laminar, incompressible and viscous flow on a continuous stretching cylinder as in figure (1).It is assumed that the stretching velocity $\mathrm{U}_{\mathrm{w}}(\mathrm{x}, \mathrm{t})=(\mathrm{a} x) /\left(1-\gamma \mathrm{t}\right.$ and the surface temperature $\mathrm{T}_{\mathrm{w}}(\mathrm{x}, \mathrm{t})$ $=(\mathrm{b} x) /(1-\gamma \mathrm{t})$, where $\mathrm{a}, \mathrm{b}$ and $\gamma$ are constants. The $\mathrm{x}$-axis and $r$-axis are taken as shown in Fig. 1. The conservation equations for this case are Equation (1 to 3):

$\frac{\partial}{\partial \mathrm{r}}(\mathrm{ru})+\frac{\partial}{\partial \mathrm{r}}(\mathrm{rv})=0$

$\frac{\partial u}{\partial t}+u \frac{\partial u}{\partial x}+v \frac{\partial u}{\partial r}=\frac{v}{r} \frac{\partial}{\partial r}\left(r \frac{\partial u}{\partial r}\right)$

$\frac{\partial \mathrm{T}}{\partial \mathrm{t}}+\mathrm{u} \frac{\partial \mathrm{T}}{\partial \mathrm{x}}+\mathrm{v} \frac{\partial \mathrm{T}}{\partial \mathrm{r}}=\frac{\mathrm{a}}{\mathrm{r}} \frac{\partial}{\partial \mathrm{r}}\left(\mathrm{r} \frac{\partial \mathrm{T}}{\partial \mathrm{r}}\right)$

Subjected to The boundary conditions Equation (4):

$\mathrm{u}=\mathrm{U}_{\mathrm{w}}(\mathrm{x}), \mathrm{v}=0, \mathrm{~T}=\mathrm{T}_{\mathrm{w}}(\mathrm{x}), \quad$ at $\mathrm{r}=\mathrm{R}$

$\mathrm{u} \rightarrow 0, \mathrm{~T} \rightarrow \infty$ as $\mathrm{r} \rightarrow \mathrm{R}$

where, $\mathrm{u}$ and vare velocity components in the $x$ and $r$ directions, respectively, $\mathrm{T}$ is the fluid temperature and $\alpha$ is the thermal diffusivity. The continuity equation can be satisfied by introducing a stream function $\psi$, such that $\mathrm{u}=\frac{1 \partial \psi}{\mathrm{r} \partial \mathrm{r}}$ and $\mathrm{v}=-\frac{1 \partial \psi}{\mathrm{r} \partial \mathrm{x}}$. The momentum and energy equations can be transformed into the corresponding ordinary differential equations by the following transformations (Mahmood and Merkin (1988), Ishak (2009)) Equation (5):

$$
\begin{aligned}
& \eta=\frac{r^{2}-R^{2}}{2 R} \sqrt{\frac{U(x)}{v x}}, \psi= \\
& R \sqrt{U(x) v x} f(\eta), \theta(\eta)=\frac{T-T_{\infty}}{T_{w}-T_{\infty}}
\end{aligned}
$$

The transformed ordinary differential equations are Equation (6 and 7):

$$
\left.\begin{array}{l}
(1+2 \eta \rho) \mathrm{f}^{\prime \prime \prime}+2 \rho \mathrm{f}^{\prime \prime}+\mathrm{ff} \mathrm{f}^{\prime \prime}-\mathrm{f}^{\prime 2}-\gamma\left(\mathrm{f}^{\prime}+\frac{\eta}{2} \mathrm{f}^{\prime \prime}\right)=0 \\
(1+2 \eta \rho) \theta^{\prime \prime}+2 \rho \theta^{\prime}+\operatorname{Pr}\left(\mathrm{f} \theta^{\prime}-\mathrm{f}^{\prime} \theta\right)-\gamma \operatorname{Pr}\left(\theta+\frac{\eta}{2} \theta^{\prime}\right)=0
\end{array}\right\}
$$

where, $(\mathrm{pr})=(v / \alpha)$ is the prandtl number

Subjected to the boundary conditions Equation (8):

$$
\begin{aligned}
& \mathrm{f}(0)=0, \mathrm{f}^{\prime}(0)=1, \theta(0)=1 \\
& \mathrm{f}^{\prime}(\infty) \rightarrow 0, \theta(\infty) \rightarrow 0
\end{aligned}
$$

where, primes denotes differentiation with respect to $\eta$ and $\rho$ denotes the curvature parameter defined as Equation (9):

$$
\rho=\sqrt{\frac{v(1-\gamma t)}{\alpha R^{2}}}
$$

The physical quantities of interest are the skin friction coefficient $\mathrm{C}_{\mathrm{f}}$ and the local Nusselt number $\mathrm{Nu}_{\mathrm{x}}$, which are defined as Equation (10):

$$
\mathrm{C}_{\mathrm{f}}=\frac{\tau_{\mathrm{w}}}{\rho \mathrm{U}^{2} \backslash 2}, \mathrm{Nu}_{\mathrm{x}}=\frac{\mathrm{xq}_{\mathrm{w}}}{\mathrm{k}\left(\mathrm{T}_{\mathrm{w}}-\mathrm{T}_{\infty}\right)}
$$

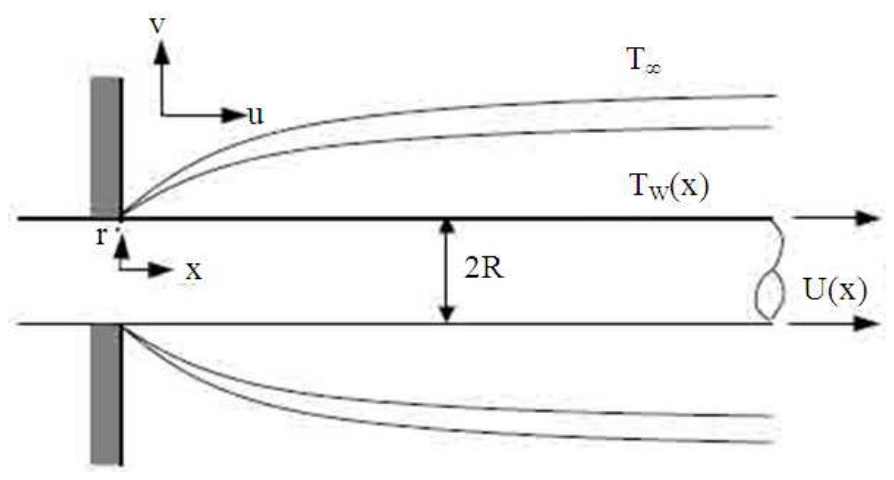

Fig. 1. Physical problem 
where, the surface shear stress $\tau_{\mathrm{w}}$ and the surface heat flux qw are given by Equation (11):

$$
\tau_{\mathrm{w}}=\mu\left(\frac{\partial \mathrm{u}}{\partial \mathrm{r}}\right)_{\mathrm{r}=\mathrm{R}}, \mathrm{q}_{\mathrm{w}}=-\mathrm{k}\left(\frac{\partial \mathrm{T}}{\partial \mathrm{r}}\right)_{\mathrm{r}=\mathrm{R}}
$$

With $\mu$ and $\mathrm{k}$ being the dynamic viscosity and the thermal conductivity, respectively. Using the similarity variables (5) we get Equation (12):

$$
\frac{1}{2} C_{f} \operatorname{Re}_{x}^{112}=f^{\prime \prime}(0), N u_{x} \backslash \operatorname{Re}_{x}^{112}=-\theta^{\prime}(0)
$$

where, $\operatorname{Re}_{\mathrm{x}}=\mathrm{Uw} / \mathrm{v}$ is the local Reynolds number.

\section{OPTIMAL HOMOTOPY ASYMPTOTIC METHOD (OHAM)}

Consider a differential Equation (13) in the form:

$$
\mathrm{L}(\mathrm{u}(\mathrm{t}))+\mathrm{N}(\mathrm{u}(\mathrm{t}))+\mathrm{g}(\mathrm{t})=0, \mathrm{~B}(\mathrm{u})=0
$$

where, $\mathrm{L}$ is a linear operator, $\mathrm{t}$ denotes an independent variable, $\mathrm{u}(\mathrm{t})$ is an unknown function, $\mathrm{g}(\mathrm{t})$ is a known function, $\mathrm{N}(\mathrm{u}(\mathrm{t}))$ is a nonlinear operator and $\mathrm{B}$ is a boundary operator. By means of OHAM a family of equations is constructed Equation (14):

$$
\begin{aligned}
& (1-\mathrm{p})[\mathrm{L}(\mathrm{F}(\mathrm{t}, \mathrm{p}))+\mathrm{g}(\mathrm{t})]-\mathrm{H}(\mathrm{p}) \\
& {[\mathrm{L}(\mathrm{F}(\mathrm{t}, \mathrm{p}))+\mathrm{g}(\mathrm{t})+\mathrm{N}(\mathrm{F}(\mathrm{t}, \mathrm{p}))]=0, \mathrm{~B}(\mathrm{~F}(\mathrm{t}, \mathrm{p}))=0}
\end{aligned}
$$

where, $\mathrm{p} \in[0,1]$ is an embedding parameter, $\mathrm{H}(\mathrm{p})$ is a nonzero auxiliary function for $\mathrm{p} \neq 0$ and $\mathrm{H}(0)=0, \mathrm{~F}(\mathrm{t}, \mathrm{p})$ is an unknown function. Obviously, when $\mathrm{p}=0$ and $\mathrm{p}=1$, we have Equation (15):

$$
\mathrm{F}(\mathrm{t}, 0)=\mathrm{u}_{0}(\mathrm{t}), \mathrm{F}(\mathrm{t}, 1)=\mathrm{u}(\mathrm{t})
$$

Then, as $\mathrm{p}$ increases from 0 to 1 , the solution $\mathrm{F}(\mathrm{t}, \mathrm{p})$ varies from $\mathrm{u}_{0}(\mathrm{t})$ to the solution $\mathrm{u}(\mathrm{t})$, where $\mathrm{u}_{0}(\mathrm{t})$ is obtained from (14) for $\mathrm{p}=0$ Equation (16):

$$
\mathrm{L}\left(\mathrm{u}_{0}(\mathrm{t})\right)+\mathrm{g}(\mathrm{t})=0, \quad \mathrm{~B}\left(\mathrm{u}_{0}\right)=0
$$

The auxiliary function is chosen in the form Equation (17):

$\mathrm{H}(\mathrm{p})=\mathrm{p} \mathrm{C} 1+\mathrm{p}^{2} \mathrm{C} 2+$

where, $\mathrm{C} 1, \mathrm{C} 2, \ldots \ldots$ are constants which can be determined later.

Expanding $F(t, p)$ in a series with respect to $p$, we get Equation (18):

$\mathrm{F}\left(\mathrm{t}, \mathrm{p}, \mathrm{C}_{\mathrm{i}}\right)=\mathrm{u}_{0}(\mathrm{t})+\sum_{\mathrm{k} \geq 1} \mathrm{u}_{\mathrm{k}}\left(\mathrm{t}, \mathrm{C}_{\mathrm{i}}\right) \mathrm{p}^{\mathrm{k}} \mathrm{i}=1,2$

Substituting (18) in (14), collecting the same powers of $p$ and equating each coefficient of $p$ to zero, we obtain a set of differential equations with boundary conditions. Solving differential equations with boundary conditions:

$$
\mathrm{u}_{0}(\mathrm{t}), \mathrm{u}_{1}\left(\mathrm{t}, \mathrm{C}_{1}\right), \mathrm{u}_{2}\left(\mathrm{t}, \mathrm{C}_{2}\right)
$$

Is obtained. Generally the solution of (13) can be determined in the form Equation (19):

$\tilde{\mathrm{u}}^{(\mathrm{m})}=\mathrm{u}_{0}(\mathrm{t})+\sum_{\mathrm{k}=1}^{\mathrm{m}} \mathrm{u}_{\mathrm{k}}\left(\mathrm{t}, \mathrm{C}_{\mathrm{i}}\right)$

Substituting (19) in (13) we get the following residual Equation (20):

$$
\mathrm{R}\left(\mathrm{t}, \mathrm{C}_{\mathrm{i}}\right)=\mathrm{L}\left(\tilde{\mathrm{u}}^{\mathrm{m}}\left(\mathrm{t}, \mathrm{C}_{\mathrm{i}}\right)\right)+\mathrm{g}(\mathrm{t})+\mathrm{N}\left(\tilde{\mathrm{u}}^{\mathrm{m}}\left(\mathrm{t}, \mathrm{C}_{\mathrm{i}}\right)\right)
$$

If $\mathrm{R}\left(\mathrm{t}, \mathrm{C}_{\mathrm{i}}\right)=0$ then $\mathrm{u}^{(\mathrm{m})}\left(\mathrm{t}, \mathrm{C}_{\mathrm{i}}\right)$ is much closer to the exact solution to minimizing the occurred error for nonlinear problem, let Equation (21):

$$
\mathrm{J}\left(\mathrm{C}_{1}, \mathrm{C}_{2}, \ldots \ldots \ldots, \mathrm{C}_{\mathrm{m}}\right)=\int_{\mathrm{a}}^{\mathrm{b}} \mathrm{R}^{2}\left(\mathrm{t}, \mathrm{C}_{1} \mathrm{C}_{2}, \ldots \ldots \ldots, \mathrm{c}_{\mathrm{m}}\right) \mathrm{dt}
$$

where, $a$ and $b$ are values depending on the given problem. The unknown constants $\mathrm{C}_{\mathrm{i}}(\mathrm{i}=1,2 \ldots \ldots \ldots, \mathrm{m})$ can be determined from the conditions Equation (22):

$$
\frac{\partial \mathrm{J}}{\partial \mathrm{c}_{1}}=\frac{\partial \mathrm{J}}{\partial \mathrm{c}_{2}}=\ldots=0
$$

With these known constants, the approximate solution (of order m) (19) is well determined. 


\section{SOLUTION USING OHAM}

Applying (14) into (8),(9) and (10) we get Equation (23):

$$
\begin{aligned}
& (1-p)\left[f^{\prime \prime}+f^{\prime}\right]-H_{1}(p)\left[f^{\prime \prime}(1+2 \rho \eta)\right. \\
& \left.+2 \rho f^{\prime \prime}+f f^{\prime \prime}-f^{\prime 2}-\gamma f^{\prime}-\gamma \frac{\eta}{2} f^{\prime \prime}-f^{\prime \prime}-f^{\prime}\right]=0 \\
& (1-p)\left[\theta+\theta^{\prime}\right]-H_{2}(p)\left[\theta^{\prime \prime}(1+2 \rho \eta)+\right. \\
& \left.2 \rho \theta^{\prime}+\operatorname{pr}\left(f \theta^{\prime}-f^{\prime} \theta\right)-\gamma \operatorname{pr}\left(\theta+\frac{\eta}{2} \theta^{\prime}\right)-\theta^{\prime}-\theta\right]=0
\end{aligned}
$$

where, primes denote differentiation with respect to $\eta$.

Since the first two equations in (23) are identical, then we take f, $\theta, \mathrm{H}_{1}$ and $\mathrm{H}_{2}$ as following Equation (24):

$$
\begin{aligned}
& \mathrm{f}=\mathrm{f}_{0}+\mathrm{pf}_{1}+\mathrm{p}^{2} \mathrm{f}_{2} \\
& \theta=\theta_{0}+\mathrm{p} \theta_{1}+\mathrm{p}^{2} \theta_{2} \\
& \mathrm{H}_{1}(\mathrm{p})=\mathrm{pC}_{1}+\mathrm{p}^{2} \mathrm{C}_{2} \\
& \mathrm{H}_{2}(\mathrm{p})=\mathrm{pC}_{1}+\mathrm{p}^{2} \mathrm{C}_{2}
\end{aligned}
$$

Collecting same powers of $\mathrm{p}$ and solving the resulted set of differential equations we obtain:

$$
\begin{aligned}
& f=1-e^{-\eta}-\frac{1}{4} c 1 e^{-\eta}\left(-2 \gamma+2 e^{\eta} \gamma-2 \gamma \eta+\gamma \eta^{2}+4 \eta^{2} \rho\right) \\
& +\frac{1}{96} e^{-2 \eta}\left(24 \mathrm{cl}^{2} \gamma+48 c 1 e^{\eta} \gamma\right. \\
& -240 \mathrm{cl}^{2} e^{\eta} \gamma+48 \mathrm{c} 2 e^{\eta} \gamma-48 \mathrm{cl} e^{2 \eta} \gamma+216 \mathrm{cl}^{2} e^{2 \eta} \gamma-48 c 2 e^{2 \eta} \gamma \\
& -24 \mathrm{cl}^{2} e^{\eta} \gamma^{2}+24 \mathrm{cl}^{2} e^{2 \eta} \gamma^{2}+48 \mathrm{c} 1 e^{\eta} \gamma \eta-192 \mathrm{cl}^{2} e^{\eta} \gamma \eta+48 \mathrm{c} 2 e^{\eta} \gamma \eta \\
& -24 \mathrm{cl}^{2} e^{\eta} \gamma^{2} \eta-24 c 1 e^{\eta} \gamma \eta^{2}+48 \mathrm{cl}^{2} e^{\eta} \gamma \eta^{2}-24 \mathrm{c} 2 e^{\eta} \gamma \eta^{2} \\
& -12 \mathrm{cl}^{2} e^{\eta} \gamma^{2} \eta^{2}+20 \mathrm{cl}^{2} e^{\eta} \gamma^{2} \eta^{3} \\
& -3 \mathrm{cl}^{2} e^{\eta} \gamma^{2} \eta^{4}+96 \mathrm{cl}^{2} \rho-384 \mathrm{cl}^{2} e^{\eta} \rho+288 \mathrm{cl}^{2} e^{2 \eta} \rho-192 \mathrm{cl}^{2} \eta \rho \\
& -96 \mathrm{c} 1 e^{\eta} \eta^{2} \rho-24 \mathrm{c} 2 e^{2 \eta} \gamma \eta^{2}-12 \mathrm{cl}^{2} e^{2 \eta} \gamma^{2} \eta^{2}+20 \mathrm{cl}^{2} e^{2 \eta} \gamma^{2} \eta^{3} \\
& -3 \mathrm{cl}^{2} e^{2 \eta} \gamma^{2} \eta^{4}+192 \mathrm{cl}^{2} e^{\eta} \eta^{2} \rho-96 \mathrm{c} 2 e^{\eta} \eta^{2} \rho-96 \mathrm{cl}^{2} e^{\eta} \gamma \eta^{2} \rho \\
& +144 \mathrm{c} 1^{2} e^{\eta} \gamma \eta^{3} \rho-24 c 1^{2} e^{\eta} \gamma \eta^{4} \rho-192 \mathrm{cl}^{2} e^{\eta} \eta^{2} \rho^{2} \\
& \left.+256 \mathrm{cl}^{2} e^{\eta} \eta^{3} \rho^{2}-48 \mathrm{c} 1^{2} e^{\eta} \eta^{4} \rho^{2}\right) \\
& \theta=e^{-\eta}+\frac{1}{4} c 3 e^{-\eta} \eta(4-4 p r-4 p r \gamma+p r \gamma \eta-8 \rho+4 \eta \rho) \\
& +\frac{1}{96} e^{-2 \eta}\left(96 \mathrm{c} 3^{2} p r-96 \mathrm{c} 3^{2} p r \eta-96 \mathrm{c} 3^{2} \mathrm{pr}^{2}\right. \\
& \theta=e^{-\eta}+\frac{1}{4} c^{3} e^{-\eta} \eta(4-4 p r-4 p r \gamma+\operatorname{pr} \eta-8 \rho+4 \eta \rho) \\
& +\frac{1}{96} \mathrm{e}^{-2 \eta}\left(96 \mathrm{c} 3^{2} \mathrm{pr}-96 \mathrm{c} 3^{2} \mathrm{pr \eta}-96 \mathrm{c} 3^{2} \mathrm{pr}^{2}\right.
\end{aligned}
$$

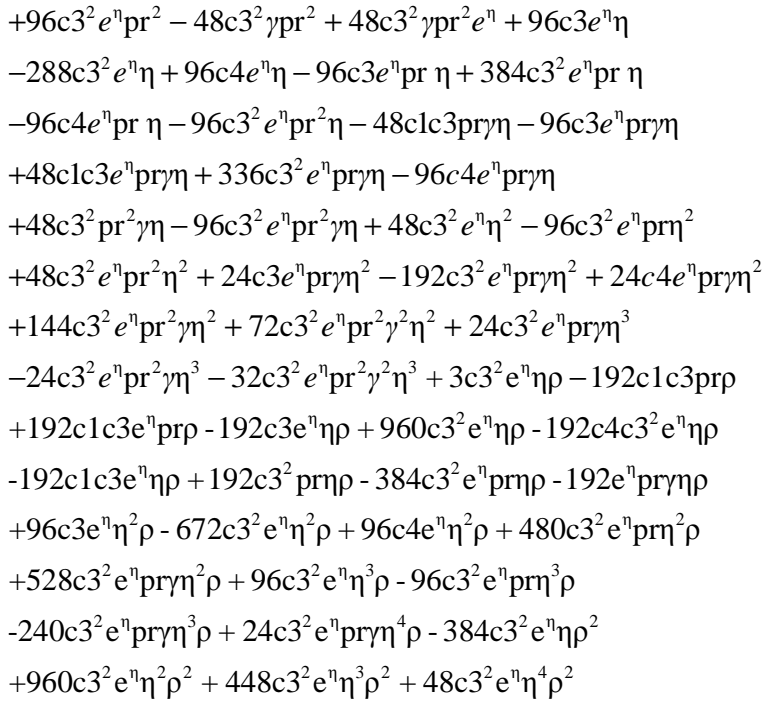

\section{RESULTS}

Computations have been carried out for various values of the dynamic parameter $(\gamma)$, the curvature parameter $(\rho)$ and the Prandtl number (pr). The Results for the skin friction $f$ " $(0)$ are computed for various values of the dynamic parameter $(\gamma)$ and the curvature parameter $(\rho)$ in Table 1 and the results for the temperature surface gradient $\theta^{\text {‘ }}(0)$ are computed for various values of the dynamic parameter $(\gamma)$, Prandtl number $(\operatorname{Pr})$ and the curvature parameter $(\rho)$ in Table 2 and 3. Moreover, the variation of velocity $f$ ' $(0)$ with the dimensionless variable $(\eta)$ for different values of the dynamic parameter $(\gamma)$ and the curvature parameter $(\rho)$ is shown in Fig. 2-4. The variation of temperature $\theta(\eta)$ with the dimensionless variable $(\eta)$ for different values of the dynamic parameter $(\gamma)$ the prandtl number $(\operatorname{Pr})$ and the curvature parameter $(\rho)$ is shown in Fig. 5-8.

\section{DISCUSSION}

This study presents the effect of unsteady motion of a stretching cylinder on the flow and heat transfer characteristics such as surface skin friction and heat flux. These characteristics have a direct effect on the quality of the final product of the fiber manufacturing and extrusion processes.

Figure 2-4 show the velocity of the boundary layer over the cylinder with the variation of dynamic parameter $\gamma$ and curvature parameter $\rho$. One can observe that the increasing of the dynamic parameter increase the velocity of the boundary layer and the increasing of curvature parameter increase the velocity to a certain value then have a reverse effect before decaying to zero. 


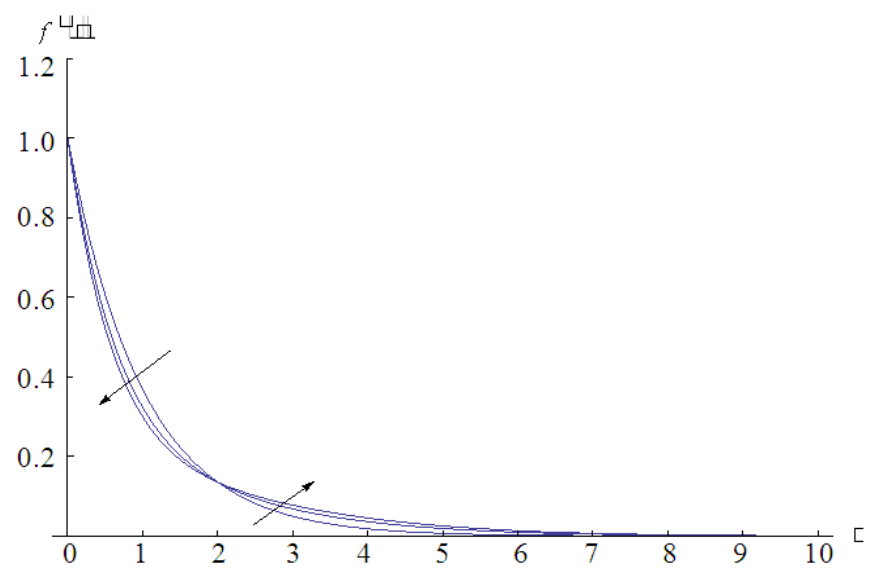

Fig. 2. Variation of the velocity $f^{\prime}(\eta)$ with the dimensionless variable $(\eta)$ for a various values of $\rho=0,0.5,1$ when $\gamma=0$

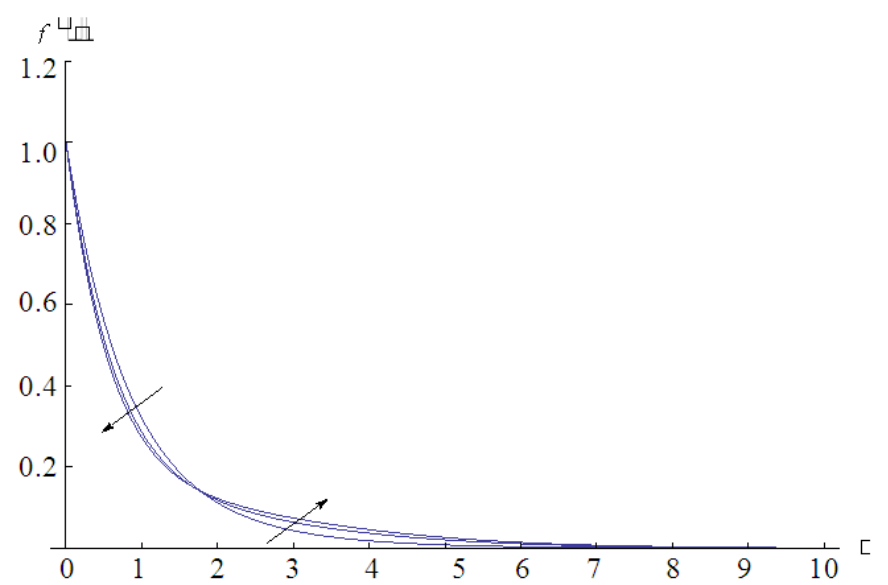

Fig. 3. Variation of the velocity $f^{\prime}(\eta)$ with the dimensionless variable $(\eta)$ for a various values of $\rho=0,0.5,1$ when $\gamma=0.5$

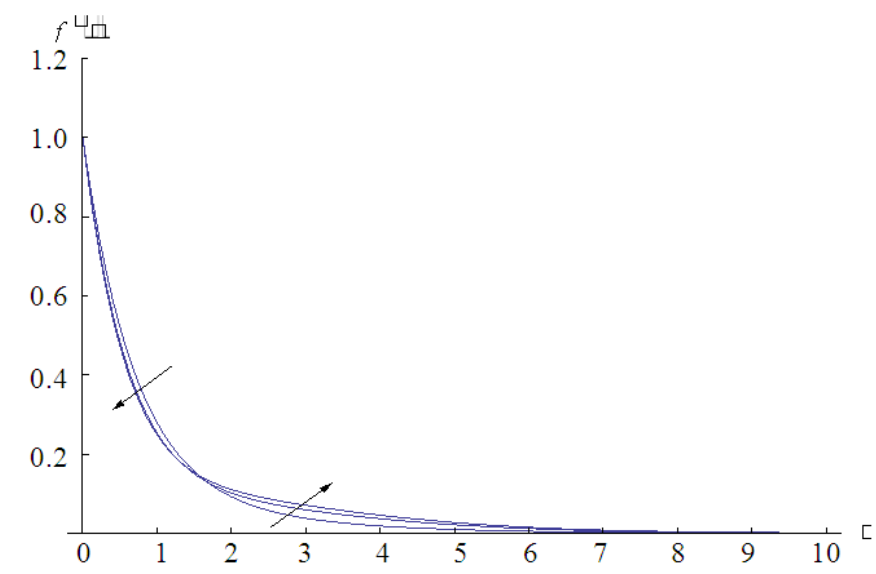

Fig. 4. Variation of the velocity $f^{\prime}(\eta)$ with the dimensionless variable $(\eta)$ for a various values of $\rho=0,0.5,1$ when $\gamma=1$ 
M.Y. Akl / Journal of Mathematics and Statistics 10 (2): 117-124, 2014

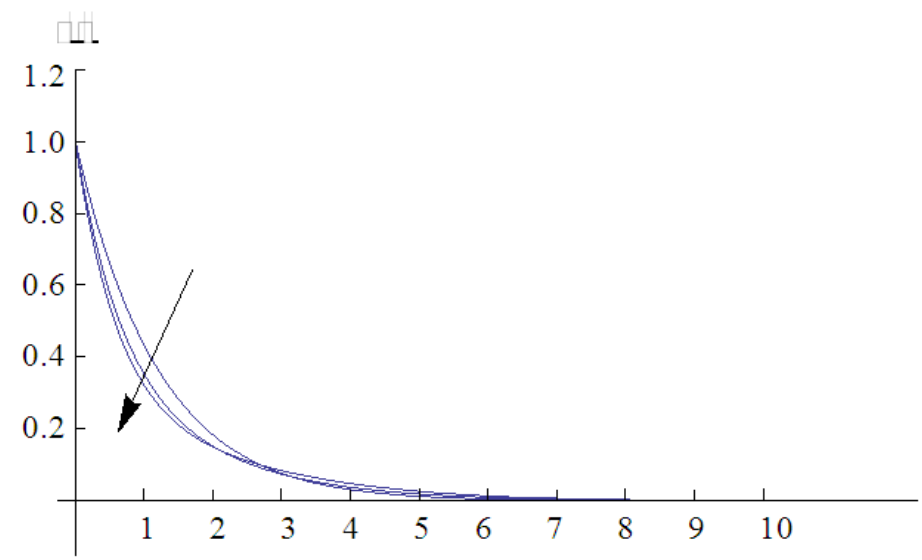

Fig. 5. Variation of temperature $\theta(\eta)$ with the dimensionless variable $(\eta)$ at $\gamma=0, p r=0.7, \rho=0,0.5,1$

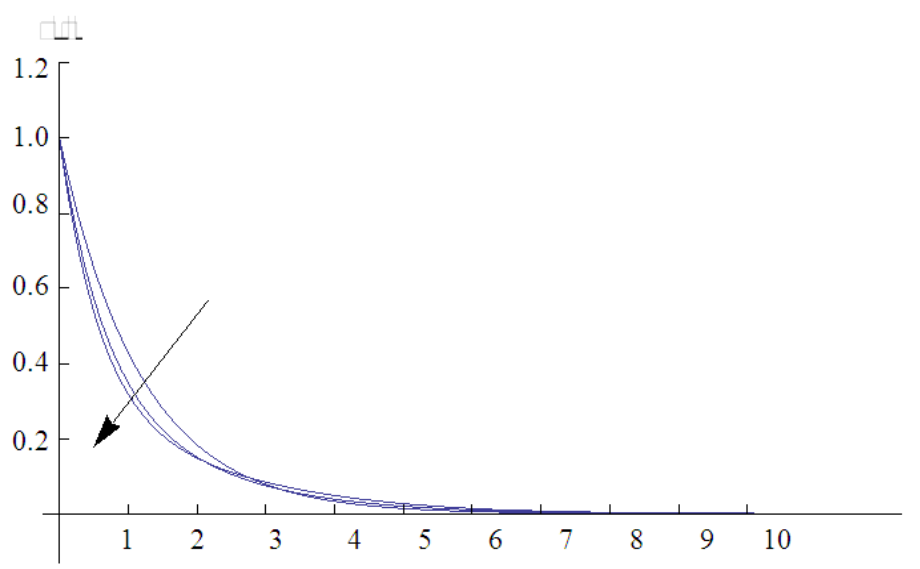

Fig. 6. Variation of temperature $\theta(\eta)$ with the dimensionless variable $(\eta)$ at $\gamma=0.1, p r=0.7, \rho=0,0.5,1$

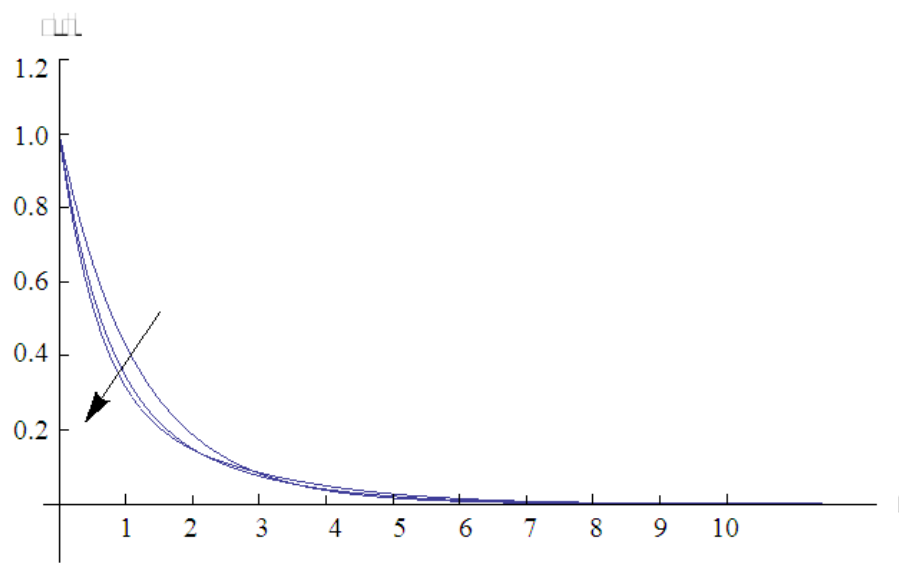

Fig. 7. Variation of temperature $\theta(\eta)$ with the dimensionless variable $(\eta)$ at $\gamma=0.2, p r=0.7, \rho=0,0.5,1$ 


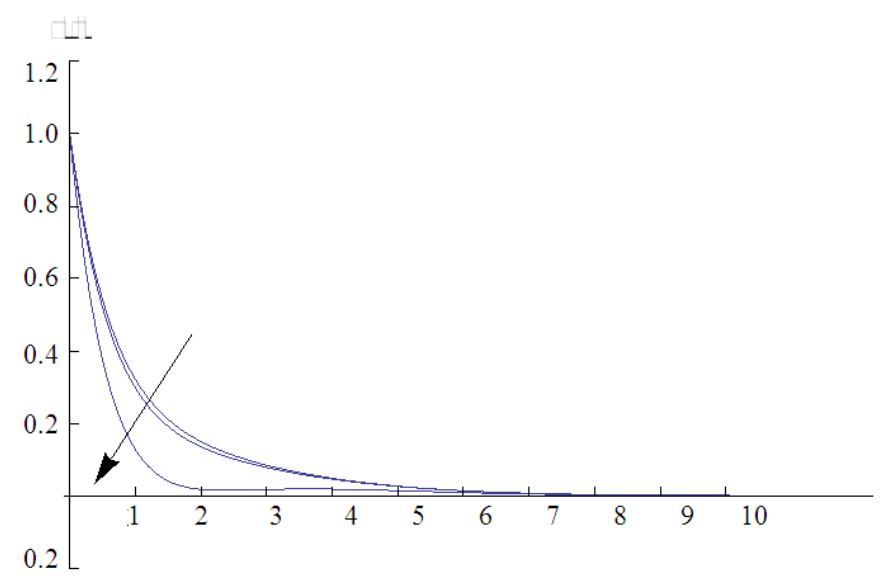

Fig. 8. Variation of temperature $\theta(\eta)$ with the dimensionless variable $(\eta)$ at $\gamma=0, \rho=1, p r=0.7,1,3$

Table 1. Variation of $f$ " ( 0$)$ for a various values of $(\rho)$ at various values of $(\gamma)$

\begin{tabular}{|c|c|c|c|}
\hline$\rho$ & $\gamma=0$ & $\gamma=0.5$ & $\gamma=1$ \\
\hline 0.0 & -1.00000 & -1.17232 & -1.32093 \\
\hline 0.5 & -1.24337 & -1.38098 & -1.49819 \\
\hline 1.0 & -1.37109 & -1.47010 & -1.55552 \\
\hline 1.5 & -1.40151 & -1.47251 & -1.73128 \\
\hline 2.0 & -1.57544 & -1.66321 & -1.74647 \\
\hline 2.5 & -1.59145 & -1.66296 & -1.73169 \\
\hline 3.0 & -1.58635 & -1.64545 & -1.70288 \\
\hline 3.5 & -1.57082 & -1.62046 & -1.66911 \\
\hline 4.0 & -1.55085 & -1.59316 & -1.63494 \\
\hline 4.5 & -1.52957 & -1.56596 & -1.60247 \\
\hline 5.0 & -1.50860 & -1.54062 & -1.57254 \\
\hline
\end{tabular}

Table 2. Variation of $-\theta^{\prime}(0)$ for a various values of $\rho, \operatorname{Pr}$ at $(\gamma=0)$

\begin{tabular}{llll}
\hline$\gamma$ & $\operatorname{Pr}$ & $\rho$ & $-\theta^{\prime}(0)$ \\
\hline 0 & 0.7 & 0.0 & 0.821030 \\
0 & 0.7 & 0.5 & 1.144430 \\
0 & 0.7 & 1.0 & 1.302190 \\
0 & 0.7 & 1.5 & 1.355360 \\
0 & 1.0 & 2.0 & 1.551810 \\
0 & 1.0 & 0.0 & 1.000000 \\
0 & 1.0 & 0.5 & 1.251980 \\
0 & 1.0 & 1.0 & 1.379360 \\
0 & 1.0 & 1.5 & 1.404660 \\
0 & 1.0 & 2.0 & 1.613150 \\
\hline
\end{tabular}

On the other hand, the effect of these parameters on the boundary layer temperature is shown in Fig. 5-7. By observing in these figures, on can observe that the increasing of both parameters increase the temperature of the boundary layer. Figure 8 shows the heat profile for various values of the prandtl number (pr), it is clear that the heat increase as the prandtl decreases. Finally Fig. 28 show the satisfaction of initial boundary conditions which support the validity of the solution.
Table 3. Variation of $-\theta^{\prime}(0)$ for a various values of $\rho$, Pr at

\begin{tabular}{llll}
\multicolumn{2}{c}{$(\gamma=0.1)$} & & \\
\hline$\gamma$ & $\operatorname{Pr}$ & $\rho$ & $-\theta^{\prime}(0)$ \\
\hline 0.1 & 0.7 & 0.0 & 0.846139 \\
0.1 & 0.7 & 0.5 & 1.164680 \\
0.1 & 0.7 & 1.0 & 1.317460 \\
0.1 & 0.7 & 1.5 & 1.365960 \\
0.1 & 0.7 & 2.0 & 1.537970 \\
0.1 & 1.0 & 0.0 & 1.045480 \\
0.1 & 1.0 & 0.5 & 1.281580 \\
0.1 & 1.0 & 1.0 & 1.400240 \\
0.1 & 1.0 & 1.5 & 1.419240 \\
0.1 & 1.0 & 2.0 & 1.592250 \\
\hline
\end{tabular}

Moreover, Table 1 shows that the skin friction coefficient $f$ " $(0)$ for all values of $\rho$ and $\gamma$ is negative which means the surface exerts a drag force on the fluid. Since Equation (6) and (7) are un coupled, then the Prandtl number does not affect on $\mathrm{f}$ " $(0)$. The absolute values of $\mathrm{f}$ "( 0$)$ for all non zero values of $\gamma$ and $\rho$ are greater than the values of $f$ " $(0)$ when $\rho=0$, which means the skin friction coefficient for the cylinder is greater than the plate. Also it is noticed that the skin friction $f$ " $(0)$ increases as the curvature parameter $(\rho)$ increases for all values of the dynamic parameter $(\gamma)$ and then the skin friction decreases as the curvature parameter $(\rho)$ increases for all values of the dynamic parameter $(\gamma)$. Table 2 and 3 show the surface heat transfer rate- $\theta$ ' $(0)$ increases as the curvature parameter $(\rho)$ increases which means also that the heat transfer rate at the surface for cylinder is greater than the heat transfer rate at the surface for the plate.

\section{CONCLUSION}

Optimal Homotopy Analysis Method has been applied to study the effects of the dynamic parameter $(\gamma)$, the 
curvature parameter $(\rho)$ and the prandtl number (pr) on the velocity and the heat transfer for a moving cylinder through the boundary layer in case of an unsteady flow.

It is found:

- Closed form solutions for (f) and $(\theta)$ are obtained

- It is found that there are considerable effects for these parameters on the velocity and temperature

- The heat increases as the curvature parameter increases for various values of the dynamic parameter $(\gamma)$

- 4. The effect of the preceded parameters of an unsteady flow on a moving cylinder is studied for the first time. It is found that the unsteady motion has a negative effect on the surface skin friction and a positive effect on surface heat flux

\section{REFERENCES}

Ali, M.E., 1994. Heat transfer characteristics of a continuous stretching surface. Heat Mass Transfer 29: 227-234. DOI: 10.1007/BF01539754

Ali, M.E., 2004. The buoyancy effects on the boundary layers induced by continuous surfaces stretched with rapidly decreasing velocities. Heat Mass Transfer, 40: 285-291. DOI: 10.1007/s00231-002-0405-9

Chen, C.H., 1998. Laminar mixed convection adjacent to vertical, continuously stretching sheets. Heat Mass Transfer, 33: 471-476. DOI: 10.1007/s002310050217

Chen, C.H., 2000. Mixed convection cooling of a heated, continuously stretching surface. Heat Mass Transfer, 36: 79-86. DOI: $10.1007 / \mathrm{s} 002310050367$

Crane, L.J., 1970. Flow past a stretching plate. Z. Angew. Math. Phys., 21: 645-647. DOI: 10.1007/BF01587695

Daskalakis, J.E., 1993. Free-convection effects in the boundary layer along a vertically stretching flat surface. Can. J. Phys., 70: 1253-1260. DOI: 10.1139/p92-204

Grubka, L.G. and K.M. Bobba, 1985. Heat transfer characteristics of a continuous, stretching surface with variable temperature. J. Heat Transfer, 107: 248-250. DOI: $10.1115 / 1.3247387$
Ishak, A. and Nazar, R. 2009. Laminar boundary layer flow along a stretching cylinder. Eur. J. Scient. Res., 36: 22-29.

Ishak, A., 2009. Mixed convection boundary layer flow over a vertical cylinder with prescribed surface heat flux. J. Phys. A, 42: 195501-195501. DOI: 10.1088/1751-8113/42/19/195501

Ishak, A., R. Nazar and I. Pop, 2007. Mixed convection on the stagnation point flow toward a vertical, continuously stretching sheet. J. Heat Transfer, 129: 1087-1090. DOI: 10.1115/1.2737482

Lin, C.R. and C.K. Chen, 1998. Exact solution of heat transfer from a stretching surface with variable heat flux. Heat Mass Transfer, 33: 477-480. DOI: 10.1007/s002310050218

Lin, H.T. and Y.P. Shih, 1980. Laminar boundary layer heat transfer along static and moving cylinders. J. Chin. Inst. Eng., 3: 73-79. DOI: 10.1080/02533839.1980.9676650

Lin, H.T. and Y.P. Shih, 1981. Buoyancy effects on the laminar boundary layer heat transfer along vertically moving cylinders. J. Chin. Inst. Eng., 4: 47-51. DOI: 10.1080/02533839.1981.9676667

Mahmood, T. and J.H. Merkin, 1988. Similarity solutions in axisymmetric mixed-convection boundary-layer flow. J. Eng. Math., 22: 73-92. DOI: 10.1007/BF00044366

Partha, M.K., P.V.S.N. Murthy and G.P. RaJasekhar, 2005. Effect of viscous dissipation on the mixed convection heat transfer from an exponentially stretching surface. Heat Mass Transfer, 41: 360-366. 10.1007/s00231-004-0552-2

Sakiadis, B.C., 1961. Boundary-layer behavior on continuous solid surfaces: I. Boundary-layer equations for two-dimensional and axisymmetric flow. AIChE J. 7: 26-28. DOI: 10.1002/aic.690070108

White, F.M., 2006. Viscous Fluid Flow. 3rd Edn., McGraw Hill, New York, ISBN-10: 007124493X, pp: 629. 